\title{
ESTUDO, EM PLANTA PILOTO, DA RELAÇÃO PROCESSO, MICROESTRUTURA E PROPRIEDADES DE AÇOS MICROLIGADOS PROCESSADOS POR LAMINAÇÃO CONVENCIONAL E TERMOMECÂNICA*
}

Carolina Elgert ${ }^{1}$

Felipe Carvalho ${ }^{2}$ Ana Paola Braga ${ }^{3}$

Felipe Bastos ${ }^{4}$

José Roberto Bolota ${ }^{5}$

Leila Teichmann ${ }^{6}$

\begin{abstract}
Resumo
A influência dos parâmetros termomecânicos e da adição de elementos microligantes na relação processo, microestrutura e propriedades de chapas laminadas, do aço DIN $20 \mathrm{MnCr} 5$ foi o objetivo de estudo deste trabalho. Os testes foram desenvolvidos em escala piloto, no laboratório de processos metalúrgicos do IPT. Foram testadas variações de composição química, condições de laminação e taxas de resfriamento. Ocorreu alongamento dos grãos austeníticos para os materiais processados por laminação termomecânica e refino de grão e aumento de limite de escoamento para os aços microligados, tanto na condição de laminação convencional, quanto na condição de laminação termomecânica.

Palavras-chave: Barras de aços especiais; Aços microligados; Laminação termocontrolada.

\section{STUDY, IN PILOT PLANT, OF THE RELATIONSHIP PROCESS, MICROSTRUCTURE AND PROPERTIES OF MICROALLOYED STEELS PROCESSED BY CONVENTIONAL AND THERMOMECHANICAL ROLLING}

\begin{abstract}
The influence of the thermomechanical parameters and microalloying elements on the relationship between process, microstructure and properties of DIN 20MnCr5 steel plates was the objective of this work. The tests were developed on a pilot scale, at IPT metallurgical process laboratory. Variations of chemical composition, rolling conditions and cooling rates were tested. It was observed elongation of austenitic grains for the materials processed by thermomechanical rolling and grain refinement and increase of yield strength for microalloyed steels at both conventional and thermomechanical rolling conditions.

Keywords: Special bar quality; Microalloyed steels; Thermo-controlled rolling.

1 Eng. Materiais, MSc, doutoranda, Assessora Técnica de Pesquisa, Desenvolvimento e Inovação, Gerdau Aços Especiais Brasil S.A, Charqueadas-RS, Brasil

Eng. Materiais, Mestrando, Instituto de Pesquisas Tecnológicas, São Paulo-SP, Brasil

3 Eng. Materiais, MSc, doutoranda, Instituto de Pesquisas Tecnológicas, São Paulo-SP, Brasil

4 Eng. Mecânico, MSc, doutorando, Espanha.

5 Eng. Metalúrgico, Consultor, CBMM, São Paulo-SP, Brasil.

6 Eng. Materiais, MSc, doutoranda, Assessora Técnica de Pesquisa, Desenvolvimento e Inovação, Gerdau Aços Especiais Brasil S.A, Charqueadas-RS, Brasil.
\end{abstract}




\section{INTRODUÇÃO}

Os fundamentos da metalurgia que envolvem 0 processo de laminação termocontrolada (TMP - Thermomechanical Processing) têm sido bastante investigados nas últimas décadas no sentido de compreender a influência da deformação, temperatura e cinética da recristalização durante a conformação mecânica dos aços, visando o refino de grão [1-3].

Antes da compreensão do processo, é importante ressaltar que durante décadas uma das principais maneiras de elevar a tensão de escoamento de um aço era aumentando o teor de carbono. De fato, com o aumento do teor de carbono, é possível aumentar a tensão de escoamento de um material laminado, em função do aumento do percentual de perlita, porém neste caso, a tenacidade tende a decrescer. Além da transformação de fases, os outros mecanismos endurecimento possíveis são encruamento, solução sólida, precipitação e refino de grão. Dentre eles, o refino de grão tem se mostrado como o mais eficiente, já que é o único que pode aumentar a tensão de escoamento simultaneamente com a tenacidade.

Durante o processo de laminação a quente dos aços, a austenita está sendo sujeita a processos subsequentes de endurecimento (encruamento) e amolecimento (recristalização). $O$ endurecimento acontece por acúmulo de defeitos cristalinos, durante a conformação a quente, e o amolecimento por recristalização. A Figura 1 mostra um desenho esquemático destes mecanismos ocorrendo entre passes sucessivos do processo de laminação [4].

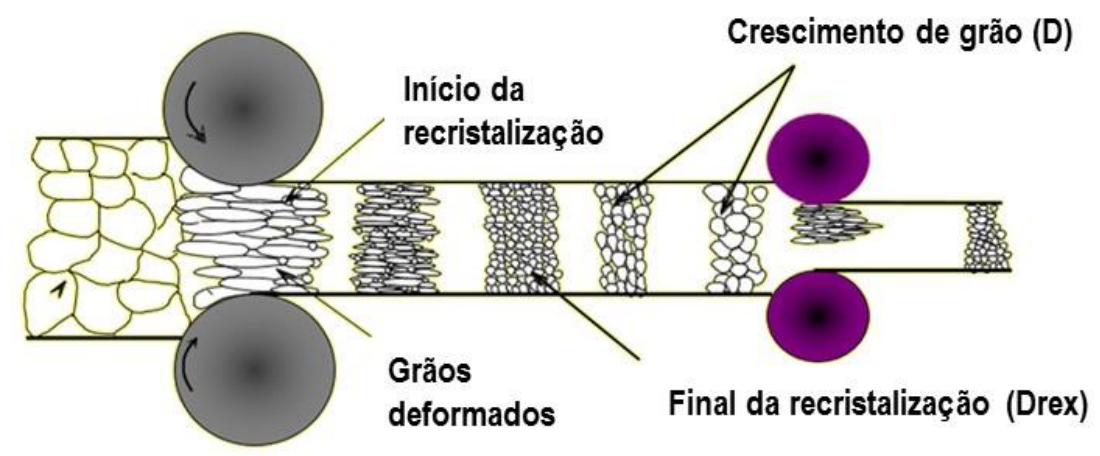

Figura 1: Desenho esquemático dos mecanismos de encruamento e recristalização ocorrendo entre passes sucessivos do processo de laminação a quente [4].

Por ser um processo termicamente ativado, nas temperaturas tradicionais de laminação a recristalização é favorecida, se não houver nenhum impedimento físico à movimentação de interfaces, como ancoramento de contornos de grão por partículas de segunda fase por exemplo. Além da temperatura, a deformação aplicada também favorece o processo de recristalização pela inserção de defeitos cristalinos na austenita, diminuindo da energia de ativação necessária para iniciar o processo de recristalização. Outros fatores influenciam o mecanismo de recristalização em metais e ligas deformadas são taxa de deformação, tamanho de grão inicial e composição química [5-6]. 
Quanto menor a temperatura de deformação, mais dificultoso e lento se torna a recristalização. Existem duas temperaturas críticas para 0 mecanismo de recristalização, conforme abaixo:

- Temperatura de limite de recristalização, RLT: Acima da qual recristalização completa deve ser obtida;

- Temperatura de término de recristalização, RST: abaixo da qual a recristalização deve ser suprimida.

$\mathrm{Na}$ região que compreende as temperaturas entre RLT e RST, um estado de microestrutura mista é observado, com a presença de grãos recristalizados e de grãos alongados, ou "panquecados" [7].

Para aços convencionais destinados à laminação, a recristalização deixa de ocorrer em temperaturas relativamente baixas, entre 600 e $700{ }^{\circ} \mathrm{C}$, dificultando a utilização deste processo em escala industrial, pois a resistência ao escoamento de aços nesta faixa de temperatura é relativamente elevada, aumentando, assim, consideravelmente as cargas referentes ao processo de laminação e inviabilizando o processo. Como alternativa, para que seja possível laminar em temperatura inferior a RST, é utilizada a adição de elementos fortemente formadores de carbonitretos, os quais ancoram interfaces e atrasam o processo de recristalização, elevando, assim, esta temperatura.

Diversos trabalhos indicam a potencialidade do nióbio em aumentar a RST e RLT em aços para as temperaturas usuais de laminação em aços que apresentam teores de carbono inferiores a $0,1 \%$ em massa. Além disso, também são atribuídos às ligas que contém $\mathrm{Nb}$, mecanismos de endurecimento tanto por precipitação, durante a transformação de fases de austenita para ferrita, quanto por refino de grão, pelo mecanismo de solut drag ou pelo mecanismo de precipitação induzida por deformação. Logo, o nióbio se mostra como um elemento que confere aos aços um aumento de tensão de escoamento sem decréscimo de tenacidade, sendo assim de grande importância para aços que são destinados ao processo de laminação termocontrolada [8-12].

Além do $\mathrm{Nb}$, o $\mathrm{V}$ é outro elemento que é bastante utilizado como microligante. Sua precipitação ocorre nas temperaturas de decomposição da austenita. Os precipitados são encontrados na interface de frente de crescimento da ferrita [8-10]. Apesar do vanádio aumentar a tensão de escoamento do material, decréscimo de tenacidade pode ser observado.

O processo de laminação termocontrolada consiste em determinar para um dado plano de laminação de um material as temperaturas críticas de não recristalização e estabelecer uma estratégia de deformações sucessivas em temperaturas superiores e inferiores a estas temperaturas. As deformações aplicadas em temperaturas mais altas são bastante importantes para diminuir e homogeneizar o tamanho dos grãos austeníticos entregues para a etapa seguinte. Já as deformações em temperaturas mais baixas são responsáveis pelo achatamento dos grãos austeníticos que, desta forma, apresentam mais sítios de nucleação de ferrita durante a transformação de fases. Além disso, também há restrição do crescimento dos grãos de ferrita em função da espessura dos grãos de austenita prévio [5]. 
A Figura 2 mostra um diagrama esquemático do processo termomecânico controlado e as microestruturas que podem resultar deste processo em diferentes condições de resfriamento [13].

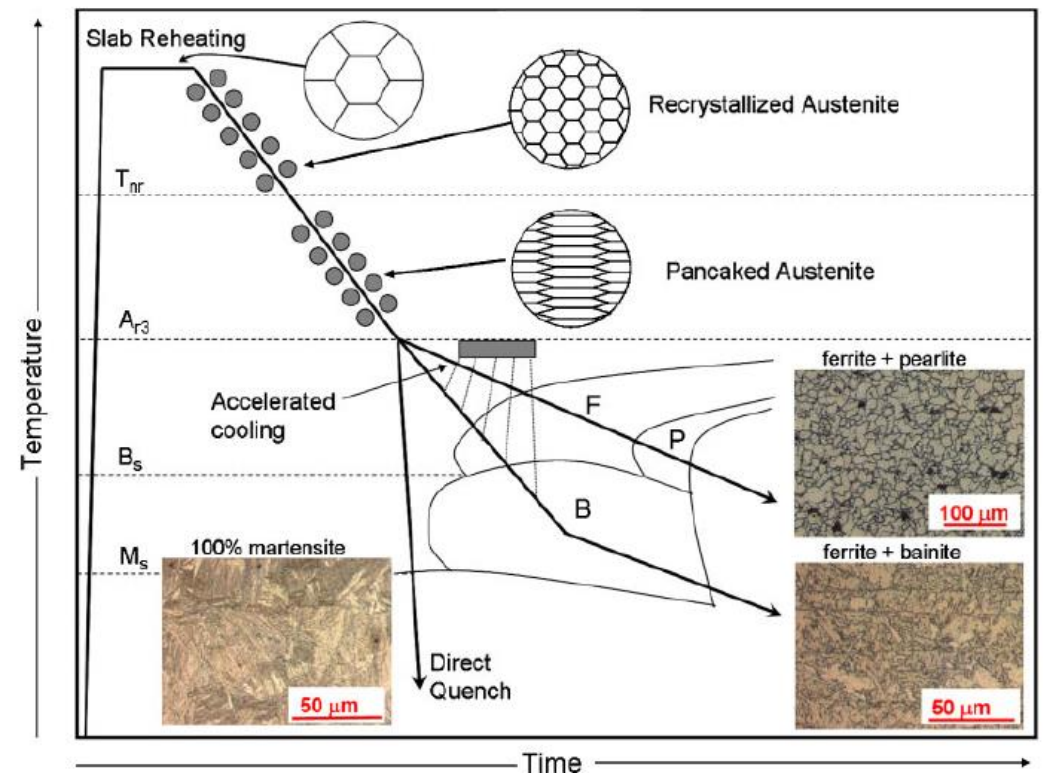

Figura 2: Diagrama esquemático do processo termomecânico controlado e a diferentes microestruturas que podem resultar deste processo [13].

O objetivo desse trabalho é estudar a influência dos parâmetros termomecânicos e da adição de elementos microligantes na relação processo, microestrutura e propriedades de chapas laminadas, do aço DIN 20MnCr5. Os testes foram desenvolvidos em escala piloto, no laboratório de processos metalúrgicos do IPT.

Essa é uma das etapas iniciais de um projeto que que visa a evolução da microestrutura e das propriedades mecânicas de aços microligados para aplicações em produtos longos especiais, objetivando eliminação de etapas posteriores de tratamento térmico e/ou melhoria de desempenho nos componentes, durante aplicação final.

\section{MATERIAIS E MÉTODOS}

\subsection{Fundição}

Três ligas que possuem como base de composição química o aço DIN $20 \mathrm{MnCr} 5$ foram utilizadas para analisar a influência da adição de Nióbio (ML1) e adição combinada de Nióbio e Vanádio (ML2) no processo de laminação termocontrolada. Os teores de Nióbio adicionados às ligas ML1 e ML2 foram equivalentes. A composição química do aço base está descrita na Tabela 1. As ligas foram fundidas e solidificadas sob vácuo (VIM - vacuum induction melting) em lingotes de $90 \mathrm{~kg}$ de seção trapezoidal. $O$ processo de manufatura das ligas foi realizado no forno de indução a vácuo do laboratório de processos metalúrgicos do IPT (LPM/IPT). A partir dos lingotes solidificados, foram cortadas placas de $19 \times 60 \times 280 \mathrm{~mm}$ na direção transversal à direção de vazamento e foram destinadas à etapa seguinte de laminação. 
Tabela 1: Composição química (porcentagem em massa) dos aços estudados.

\begin{tabular}{ccccc}
\hline & $\% \mathbf{C}$ & $\%$ Si & $\% \mathbf{M n}$ & $\% \mathbf{C r}$ \\
\hline \multirow{2}{*}{ 20MnCr5 } & 0,17 & - & 1,10 & 1,00 \\
& 0,22 & 0,40 & 1,40 & 1,30 \\
\hline
\end{tabular}

\subsection{Determinação das condições de aquecimento}

A etapa que precede a laminação consiste no aquecimento das placas. Para determinar a temperatura de aquecimento e tempo de retenção, o critério foi solubilizar os elementos microligantes $(\mathrm{V}$ e $\mathrm{Nb})$ para que pudessem ser precipitados durante a laminação e resfriamento. A abordagem foi realizada por meio da utilização de simulações termodinâmicas (Thermocalc®).

\subsection{Determinação dos parâmetros de laminação}

Foram testadas duas condições de laminação, denominadas: Laminação Convencional e Laminação Termomecânica.

O plano de deformação foi o mesmo para as duas condições de laminação, com seis passes de deformação, com deformações aplicadas em cada passe variando entre 0,14 e 0,22 .

Em relação às temperaturas de processo, as temperaturas objetivadas para os três passes iniciais foram as mesmas para as duas condições de laminação, acima da temperatura de limite de recristalização, RLT. No entanto, para laminação dos últimos três passes da condição Laminação Termomecânica, foi realizada espera para que a fosse alcançada temperatura inferior a temperatura de término de recristalização, RST. Na Figura 3 é possível observar desenho esquemático das temperaturas médias obtidas por passe em cada condição de laminação.

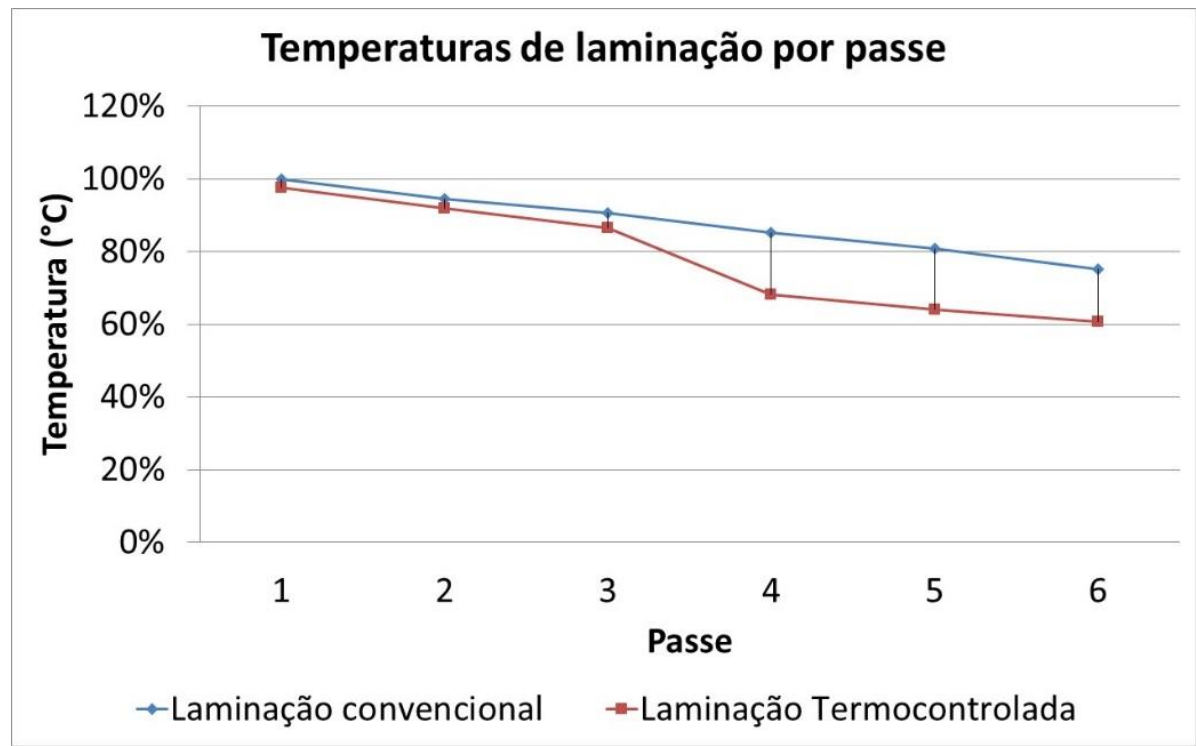

Figura 3. Representação das temperaturas médias obtidas por passe em cada condição de laminação. 
As temperaturas RLT e RST, para aços microligados ao $\mathrm{Nb}$, podem ser calculadas utilizando as equações abaixo [7].

$$
R L T\left({ }^{\circ} C\right)=174 \cdot \log \left[N b \times\left(C+12 / 14^{N}\right)\right\rfloor+1444
$$

$$
R S T\left({ }^{\circ} \mathrm{C}\right)=R L T-75
$$

Além dos parâmetros mencionados acima também foi analisado o efeito da velocidade de resfriamento após a laminação. Após laminação das placas, foram realizados resfriamentos ao ar calmo e ao ar forçado. Na condição de resfriamento ar calmo, as placas foram laminadas e expostas ao ar. Na condição ar forçado, as placas receberam um jato de ar pressurizado.

As laminações das placas foram realizadas no laminador em escala piloto do laboratório de processos metalúrgicos do IPT (LPM/IPT) STANAT duo reversível TA 315 segundo as condições apresentadas acima. A espessura final das chapas, após laminação, foi de $8 \mathrm{~mm}$.

\subsection{Parâmetros de análise microestrutural e morfológica}

Após a laminação, foram retiradas amostras para metalografia (Figura 4) e então preparadas segundo a rota tradicional de preparações de amostras metalográficas. As análises foram realizadas por microscopia óptica e microscopia eletrônica de modo a caracterizar os microconstituintes obtidos no resfriamento após a laminação e efeitos de cada processo no tamanho e morfologia do grão austenítico. Para revelação da microestrutura, foi realizado ataque com reagente Nital $3 \%$. Para revelação do tamanho de grão austenítico, o ataque químico utilizado foi uma mistura de ácido pícrico e tensoativo, em temperatura de $60^{\circ} \mathrm{C}$.

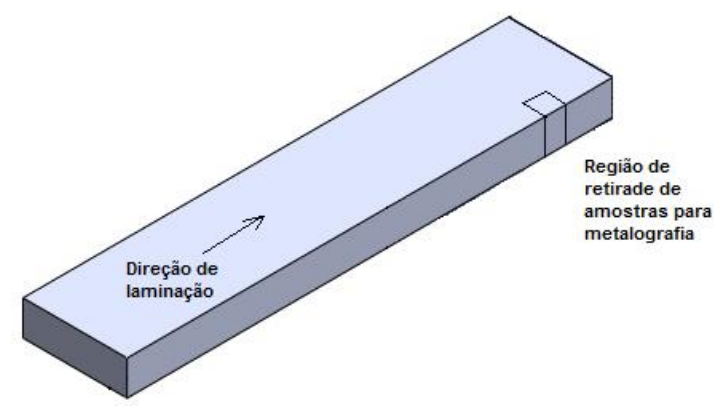

Figura 4: Região de análise microestrutural

Para análise dos grãos austeníticos foram utilizados os seguintes parâmetros:

- Alongamento: é um parâmetro que relaciona a morfologia do grão. O cálculo envolve a diferença do maior diâmetro em relação ao menor dividido pela soma de ambos. Para grãos alongados, este valor é próximo de 1 e para grãos equiaxiais é 0 .

- Diâmetro médio equivalente: é medido utilizando o cálculo de área de cada grão e então é calculado o diâmetro de uma circunferência com a área do determinado grão em questão. Estes parâmetros foram medidos para cada grão em uma área de $0,6 \mathrm{~mm}^{2}$ por condição experimental e então organizados em histogramas. 


\subsection{Ensaios Mecânicos}

Corpos de prova para ensaio mecânico (tração e impacto) foram usinados na região central da placa. Como a espessura final das placas é inferior ao diâmetro/espessura dos corpos de prova padrão de ensaios mecânicos, a norma utilizada para a medição das propriedades foi a ASTM A370 [14], onde são considerados corpos de prova de tamanho reduzido (sub-size).

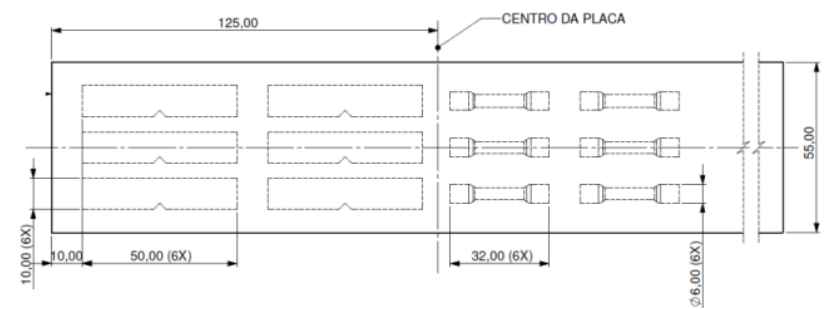

Figura 5: Posicionamento e região de retirada de corpos de prova a partir das placas laminadas.

De modo a avaliar a influência da composição química e processamento termomecânico nas propriedades mecânicas das ligas em questão, foram realizados ensaios de impacto Charpy e tração. As amostras foram usinadas segundo o esquema da Figura 5Figura . Para cada condição de processamento (laminação convencional ou termomecânica) e condição de resfriamento (ar calmo ou ar forçado), foram realizadas 3 repetições.

\section{RESULTADOS E DISCUSSÕES}

\subsection{Caracterização microestrutural}

Devido à pequena espessura final das placas laminadas $(8 \mathrm{~mm})$, a taxa de resfriamento aplicada na condição de resfriamento lento foi suficientemente elevada para que fosse possível observar a presença de ilhas de perlita degenerada e microconstituintes M/A (martensita e austenita em blocos) em meio a uma matriz ferrítica, para todas as ligas. Nas amostras resfriadas na condição de ar forçado, apesar do resfriamento ter sido realizado de maneira mais acelerada, não foi possível observar uma diferença significativa na microestrutura em relação às amostras resfriadas em ar calmo, exceto a ausência de grãos de ferrita grosseiros. A Figura 6 mostra as imagens obtidas para ML1 resfriada ao ar calmo (A) e ao ar forçado (B). 


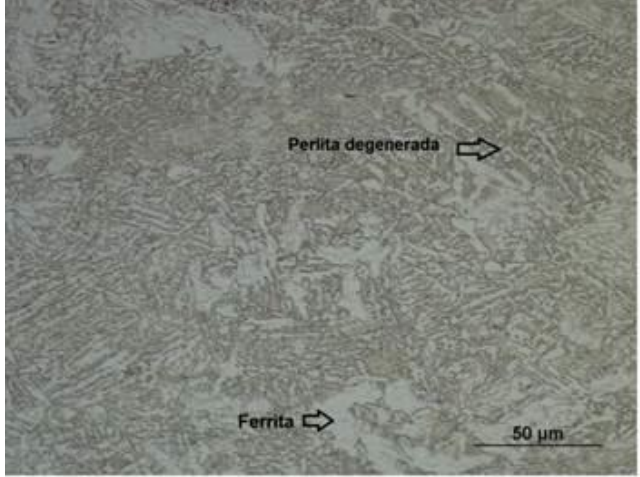

(a)

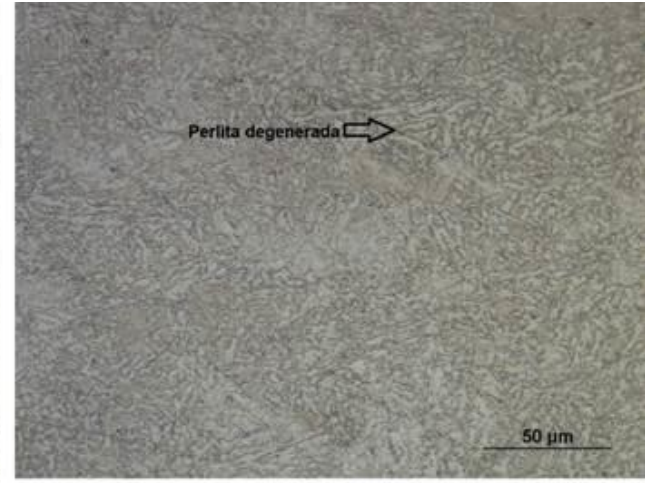

(b)

Figura 6: Microscopia da liga ML1 laminada de maneira termomecânica e resfriado ao ar calmo (A) e ar forçado (B). Aumento: 500x.

A formação de ilhas de perlita degenerada está associada à cinética necessária para a formação da estrutura clássica lamelar da perlita. Como é conhecida, a característica lamelar da perlita é atribuída ao seu mecanismo de crescimento cooperativo de lamelas de ferrita e cementita por difusão. Além de termicamente ativada, a difusão é um processo dependente do tempo. Para as amostras e micrografias apresentadas (Figura 7), o primeiro produto a se formar é a ferrita, desta forma expulsando carbono por difusão para a austenita remanescente. A austenita remanescente, rica em carbono tende a se decompor em perlita (por volta de $720^{\circ} \mathrm{C}$ segundo o diagrama de equilíbrio $\mathrm{Fe}-\mathrm{C}$ ) segundo a teoria clássica de transformação perlítica, porém quando é aplicado um resfriamento mais acelerado, a transformação perlítica é interrompida, dando assim origem a perlita degenerada. A perlita degenerada consiste em uma estrutura lamelar similar à estrutura perlítica tradicional, porém com lamelas interrompidas e de espaçamento interlamelar variável.

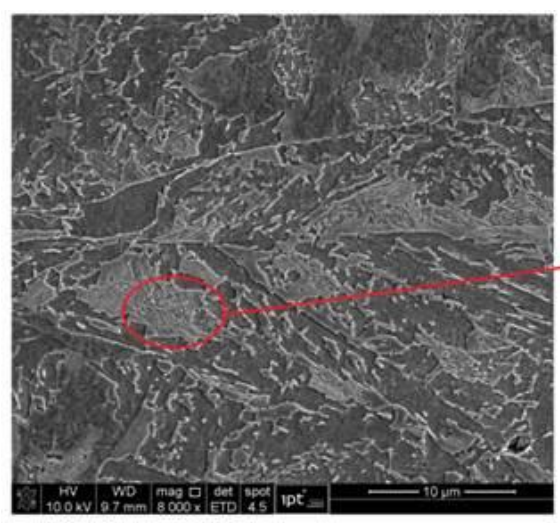

(a)

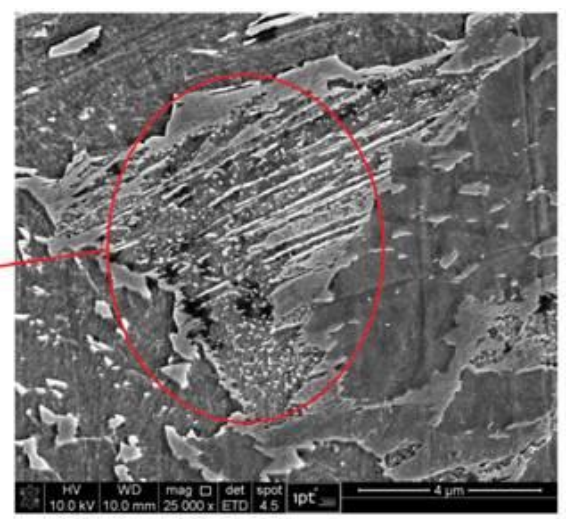

(b)

Figura 7: Microestrutura da liga ML1 laminada e resfriado ao ar calmo. Ataque químico: Nital $3 \%$. (a) microestrutura composta principalmente por ferrita e ilhas de perlita degenerada; (b) Detalhamento de uma ilha de perlita degenerada.

\subsection{Caracterização morfológica}

Na Figura 8, seguem resultados das análises dos grãos austeníticos. 

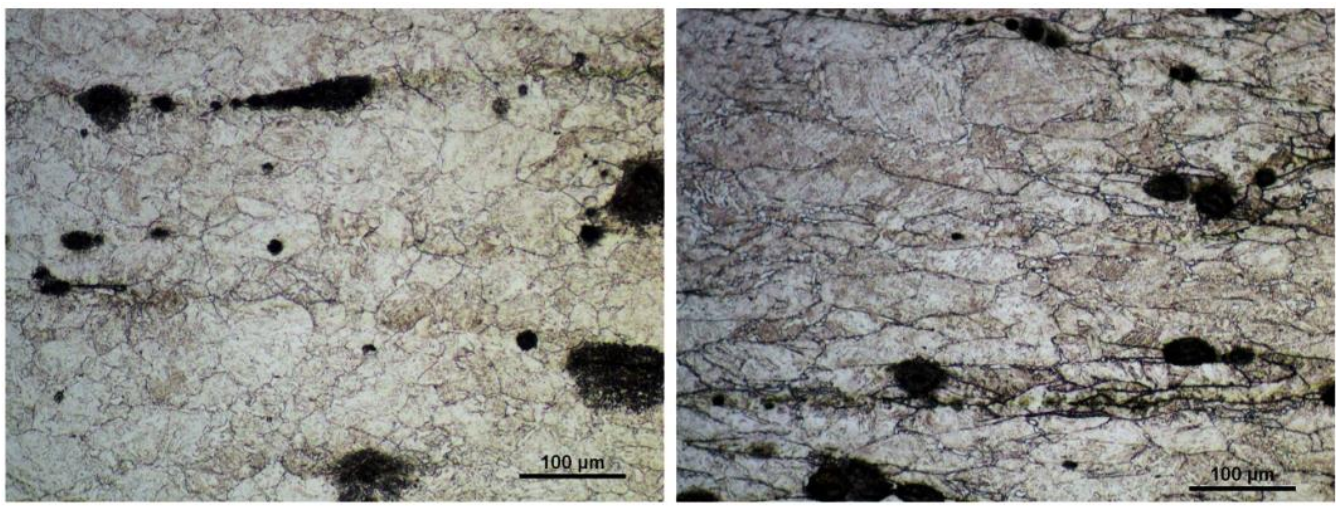

Figura 8: Exemplo de grãos austeníticos da liga ML1 revelados mostrando o grau de deformação acumulado no processo de laminação termomecânica em relação à laminação convencional (Aumento: 200x) (a) Laminação convencional; (B) Laminação termocontrolada.

As medições de tamanho (diâmetro equivalente) e morfologia (alongamento) dos grãos austeníticos foram realizadas no software de análise de imagens Aphelium® e organizadas em histogramas (Figura 9 e Figura 10), para que assim seja possível analisar indícios das consequências do processo de laminação termocontrolada.
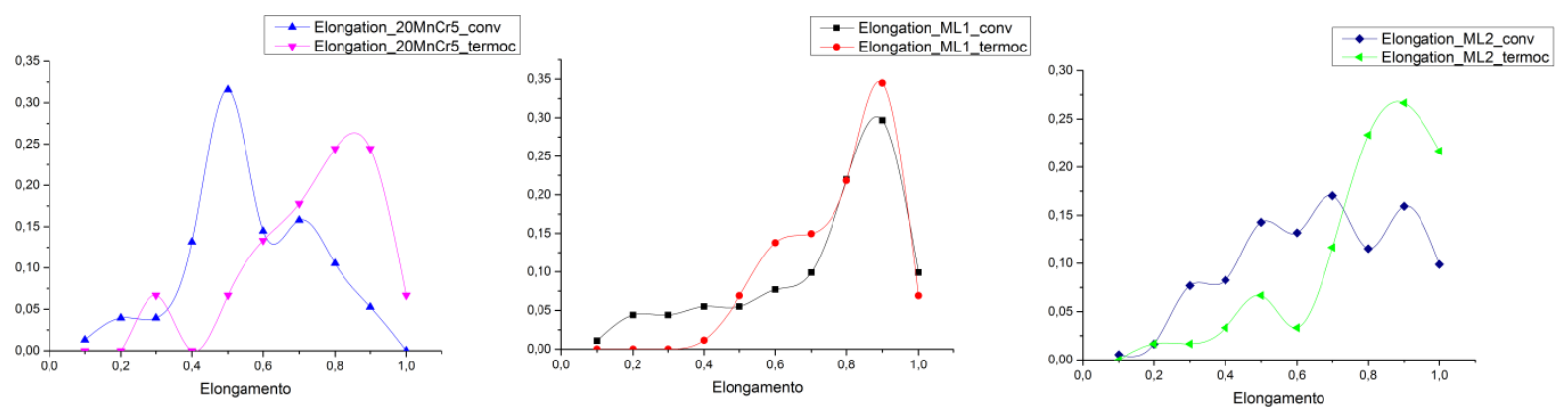

Figura 9: Distribuição das medições de alongamento apresentados como histograma.
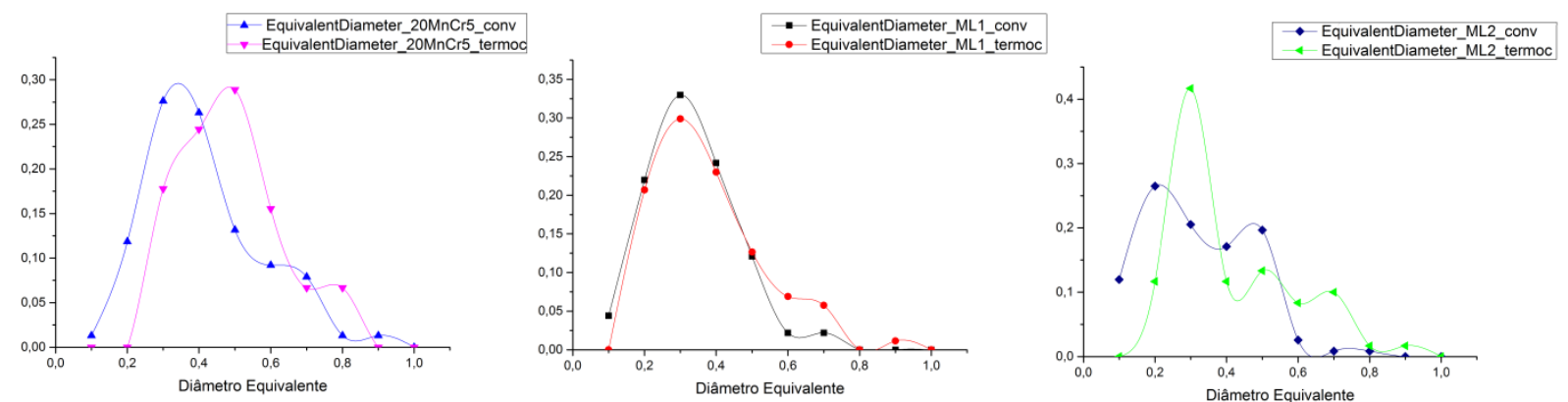

Figura 10 - Medições de diâmetro médio equivalente em $\mu$ m.

A Tabela 2 mostra os valores médios de alongamento e diâmetro equivalente obtidos para as condições testadas.

Tabela 2: Valores médios obtidos para alongamento e diâmetro médio para as condições testadas.

\begin{tabular}{ccccc}
\hline & Laminação & 20MnCr5 & ML1 & ML2 \\
\hline \multirow{2}{*}{ Alongamento } & Convencional & 0,51 & 0,68 & 0,67 \\
& Termomecânica & 0,69 & 0,73 & 0,76 \\
\hline
\end{tabular}




\begin{tabular}{ccccc}
\hline Diâmetro Equivalente & Convencional & 36,45 & 28,60 & 26,80 \\
$(\mu \mathrm{m})$ & Termomecânica & 44,50 & 32,53 & 35,38 \\
\hline
\end{tabular}

A Figura 10 mostra a distribuição do alongamento dos grãos medidos para cada liga e em cada condição de laminação. É possível observar que, no processo de laminação termomecânica, onde os corpos de prova foram laminados tanto acima da RLT quanto abaixo da RST, de fato, ocorreu alongamento dos grãos austeníticos e também foi observada uma distribuição morfológica mais estreita. Tais fatos podem ser observados quando a distribuição de alongamento se torna mais estreita e o pico deslocado para valores maiores. Quando comparamos as três ligas com processamento termomecânico, verifica-se que as ligas ML1 e ML2 apresentam uma distribuição mais estreita do que a liga base. Os valores médios informados na Tabela 2 também evidenciam estas afirmações. Não foram observadas diferenças expressivas no alongamento para as ligas ML1 e ML2.

Observando a Tabela 2, verificou-se diâmetros equivalentes médios semelhantes para as ligas ML1 e ML2 e menor quando comparado com a liga base, mesmo no material processado por laminação convencional. Também foi observado um pequeno aumento no tamanho de grão austenítico. Este fato é esperado, já que o processo de laminação termocontrolada foi executado considerando três passes em região em que não há recristalização, mas sim deformação acumulada que gera alongamento dos grãos de modo que a espessura de cada grão seja pequena o suficiente para restringir os microconstituintes nucleados a partir do grão austenítico.

\subsection{Propriedades mecânicas}

A média dos resultados de tensão de escoamento e tenacidade estão dispostos nas Figura 11. 


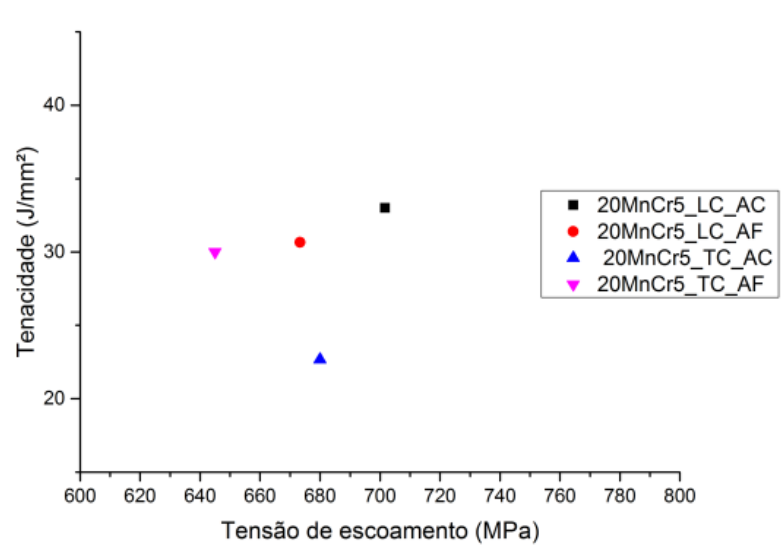

(a)

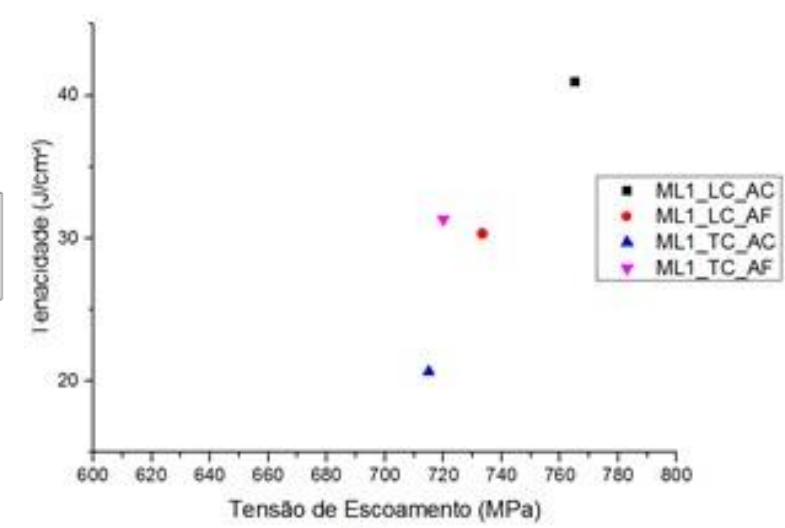

(b)

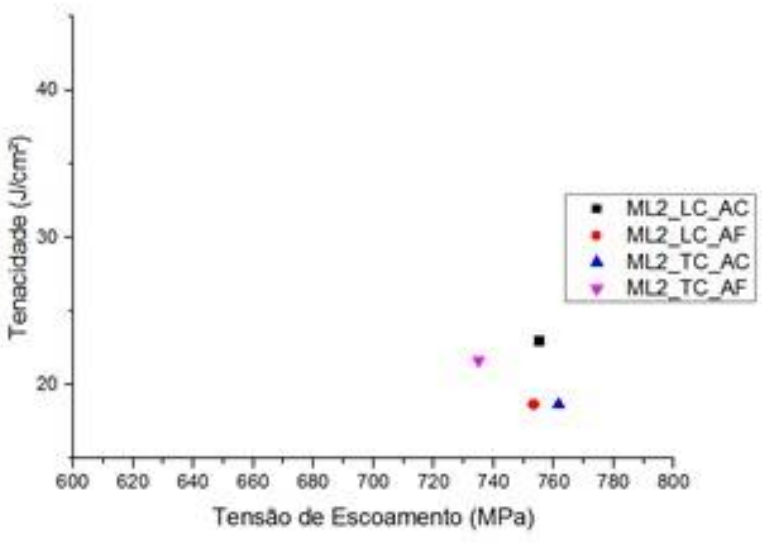

(c)

Figura 11: Resultados de tenacidade e tensão de escoamento dos corpos de prova usinados a partir das placas laminadas. (a) liga base $20 \mathrm{MnCr} 5$; (b) ML1; (c) ML2.

LC: laminação convencional; TC: laminação termocontrolada;

AC: resfriamento ao ar calmo; AF: resfriamento ao ar forçado.

Com os dados organizados em diagramas como é mostrado na Figura 11, é possível inferir que a adição de elementos microligantes (ML1 e ML2), assim como esperado, aumentou a tensão de escoamento das ligas para todas as condições de laminação e de resfriamento. Os melhores resultados foram obtidos para a liga ML1, laminada por processo termomecânico, resfriada ao ar calmo. Também foi observado que a liga contendo vanádio e nióbio apresentou menor tenacidade em relação à liga com apenas adição de nióbio e que a liga base. $O$ fato de o projeto ter sido desenvolvido em escala piloto restringe a quantidade total de deformação das placas e faz com que a taxa de resfriamento das mesmas seja bastante elevada, mesmo quando resfriadas ao ar calmo. Estes fatos podem ter tido influência sobre os resultados de propriedades mecânicas.

\section{CONCLUSÃO}

1) Ocorreu alongamento dos grãos austeníticos para os materiais processados por laminação termomecânica. Também foi observada uma distribuição morfológica mais estreita para aços microligados do que para o aço base; 
2) Os diâmetros equivalentes médios equivalentes para as ligas ML1 e ML2 são menores quando comparado com a liga base, mesmo no material processado por laminação convencional.

3) Houve um pequeno aumento no diâmetro equivalente dos grãos austeníticos quando comparamos os aços laminados pelo processo termomecânico com aços laminados pelo processo convencional.

4) Houve aumento da tensão de escoamento das amostras com a adição de elementos microligantes ( $\mathrm{Nb}$ e $\mathrm{V}$ ) para a mesma configuração de processamento

5) Os melhores resultados foram observados para a liga microligada ao $\mathrm{Nb}$, com laminação termomecânica, resfriada ao ar calmo.

6) A tenacidade diminuiu com a adição de vanádio

7) Apesar dos ensaios terem sido realizados em escala piloto, com limitações na quantidade de deformação total utilizada, foi possível perceber que o processo de laminação termocontrolada apresenta efeitos significativos na morfologia do grão austenítico entregue após a laminação. Houve um aumento significativo no grau de alongamento dos grãos, o qual restringe 0 crescimento de produtos decorrentes da decomposição da austenita durante o resfriamento, refinando assim a microestrutura final.

\section{Agradecimentos}

Os autores gostariam de agradecer a Gerdau, ao IPT e a CBMM pelo apoio no desenvolvimento deste trabalho.

\section{REFERÊNCIAS}

1 JIANG, Min et al. Effect of controlled rolling/controlled cooling parameters on microstructure and mechanical properties of the novel pipeline steel. Advances in Manufacturing, v. 2, n. 3, p. 265-274, 2014

2 HALFA, Hossam. Recent trends in producing ultrafine grained steels. Journal of Minerals and Materials Characterization and Engineering, v. 2014, 2014

3 OPIELA, M. Effect of thermomechanical processing on the microstructure and mechanical properties of $\mathrm{Nb}-\mathrm{Ti}-\mathrm{V}$ microalloyed steel. Journal of materials engineering and performance, v. 23, n. 9, p. 3379-3388, 2014

4 STTALHEIM, D. G.; BASTOS, F. M. M. M. Microalloying application in structural steels hot rolling of microalloyed steels. In: ABM WEEK 2016, 2016, Rio de Janeiro. Anais.

5 TAMURA, Imao; SEKINE, Hiroshi; TANAKA, Tomo. Thermomechanical processing of high-strength low-alloy steels. Butterworth-Heinemann, 2013

6 ROUCOULES, C. et al. Softening and microstructural change following the dynamic recrystallization of austenite. Metallurgical and Materials transactions A, v. 25, n. 2, p. 389-400, 1994

$7 \quad$ Bai D., Bodnar R., Ward J., Dorricott, J. Development of Discrete X80 Line Pipe Plate at SSAB. In International Simposium on the Recent Developments in Plate Steels. 2011 
8 BATTE, A. D.; HONEYCOMBE, R. W. K. Strengthening of ferrite by vanadium carbide precipitation. Metal Science Journal, v. 7, n. 1, p. 160-168, 1973.

9 LI, P.; TODD, J. A. Application of a new model to the interphase precipitation reaction in vanadium steels. Metallurgical and Materials Transactions A, v. 19, n. 9, p. 2139-2151, 1988.

10 ROUCOULES, C.; YUE, Steve; JONAS, John J. Microstructural changes following dynamic recrystallization in microalloyed austenite. In: Materials Science Forum. Trans Tech Publications, 1993. p. 455-460.

11 TANAKA, T. Controlled rolling of steel plate and strip. International metals reviews, v. 26, n. 1, p. 185-212, 1981

12 SUBRAMANIAN, S. V. et al. Ultra-fine grain size by dynamic recrystallization in strip rolling of $\mathrm{Nb}$ microalloyed steel. In: Materials Science Forum. Trans Tech Publications, 2005. p. 141-144.

13 S. V Vervynckt, K. Verbeken, B. Lopez and J. J. Jonas, Modern HSLA steels and role of non-recrystallisation temperature, International Materials Reviews 2012 VOL 57 NO 4, pp. 187-207

14 AMERICAN SOCIETY FOR TESTING AND MATERIALS. ASTM A370: Standard Test Methods and Definition for Mechanical Testing of Steel Products. Philadelphia, 2012. 